\title{
Effect of chamber characteristics, incubation, and diluent on motility of honey bee (Apis mellifera) drone sperm
} updates

\author{
Jesús YÁniz ${ }^{1}$, Inmaculada Palacín ${ }^{2}$, Pilar Santolaria $^{2}$ \\ ${ }^{1}$ Department of Animal Production and Food Sciences, EPSH, University of Zaragoza, Ctra. Cuarte S/N, 22071, Huesca, \\ Spain \\ ${ }^{2}$ BIOFITER Research Group, Environmental Sciences Institute (IUCA), Department of Animal Production and Food \\ Sciences, University of Zaragoza, Huesca, Spain
}

Received 14 October 2018 - Revised 1 April 2019 - Accepted 3 June 2019

\begin{abstract}
In this study, we compared the effect of five different sample viewing devices (slide coverslips, Makler, Leja10, Leja20, and ISAS10 chambers), incubation time, analysis time, microscopic field analysis, and diluent used on honey bee semen motility parameters. Using media without proteins, a lower proportion of total motile and of freely motile sperm (those non-adhering to the glass surface) were observed for slide coverslip and slide coverslipMakler chambers, respectively, than in other chambers, while the percentage of circular sperm followed an opposite trend. Significant increases in all motility parameters were observed when loaded Leja10 chambers were maintained at $35^{\circ} \mathrm{C}$. During microscopic field analysis in the Leja Chamber, the percentage of freely motile sperm decreased and those of circular sperm increased in the last fields evaluated. The addition of $2 \%$ of BSA to the diluent clearly reduced the sperm adhesion to glass surface when using slide coverslip and Makler chambers. This study confirms that the choice of chamber and diluent used to assess honey bee drone sperm motility has a significant effect on the results wherein traditional slide coverslips are contraindicated.
\end{abstract}

\section{Apis mellifera iberiensis / sperm / motility}

\section{INTRODUCTION}

The need to retain viable sperm for several years in honey bee queen spermathecae requires highquality sperm. The quality of sperm produced by drones is essential to the reproductive success of the queen and may determine the colony's survival and level of productivity (Pettis et al. 2016), as well as the success of instrumental insemination (Collins 2000; Collins 2004a).

In this context, the study of drone sperm quality is of great interest, both in basic and applied studies. In fact, sperm quality has been used to study the effect of the following: age (Locke and Peng 1993;

Corresponding author: J. Yániz, jyaniz@unizar.es Handling editor: David Tarpy
Rhodes et al. 2011; Stürup et al. 2013; Rousseau et al. 2015), body size (Schluns et al. 2003), genetics (Rhodes et al. 2011; Rousseau et al. 2015), temperature (Czekonska et al. 2013a; Stürup et al. 2013), nutrition (Stürup et al. 2013), management (Ben Abdelkader et al. 2014; Czekonska et al. 2015), seasonal variations (Zaitoun et al. 2009; Rhodes et al. 2011), disease (DelCacho et al. 1996; Collins and Pettis 2001), insecticides (Ciereszko et al. 2017; Gajger et al. 2017), miticides (Johnson et al. 2013), semen storage in liquid and frozen states (Locke and Peng 1993; Taylor et al. 2009; Hopkins and Herr 2010; Wegener et al. 2012; Hopkins et al. 2017), semen handling (Locke and Peng 1993; Collins 2003; Collins 2004b), sperm competition (Shafir et al. 2009), and physiology (den Boer et al. 2009).

Despite its importance, considerably less knowledge is available about the quality of honey 
bee drone semen compared with domestic mammal species. Most studies into drone semen quality have only assessed a few parameters such as sperm volume, sperm concentration and/or sperm membrane integrity, which is also known as sperm viability (Collins and Pettis 2001; Lodesani et al. 2004; Taylor et al. 2009; Czekonska et al. 2013b; Rousseau et al. 2015; Ciereszko et al. 2017). Some authors have investigated other parameters such as the assessment of certain molecules in sperm (Marti et al. 1996; Wegener et al. 2012; Ben Abdelkader et al. 2014), the mitochondrial membrane potential (Ciereszko et al. 2017), the proportion of DNA damage (Wegener et al. 2014) and the effect different kinds of stress on spermatozoa (Nur et al. 2012; Wegener et al. 2012).

Honey bee drone sperm motility has also been assessed in a few studies (Locke and Peng 1993; Taylor et al. 2009; Wegener et al. 2012; Ciereszko et al. 2017), but the volume of data collated is far from that gathered for mammals where sperm motility is one of the most widely used parameters to determine sperm quality (Yaniz et al. 2018). Sperm motility is a prerequisite for sperm migration to the queen's spermatheca and for subsequent egg fertilization and should be considered an essential characteristic of sperm quality. Wegener et al. (2012) found that sperm motility showed a stronger correlation with sperm performance indicators in inseminated queens than other parameters of sperm quality, including the conventional viability assay. However, strict control over factors that can potentially affect sperm motility is essential to obtain reliable results (Yaniz et al. 2018). The method used to assess sperm motility in drones has mainly been based on the use of slide coverslips, with or without sample incubation before or after loading it in the chamber. The kind of chamber must be determined carefully based on each species' semen characteristics (Verstegen et al. 2002). The aim of the present work is to contribute to the standardization of honey bee drone sperm motility assessment by studying the effect of the viewing chamber, incubation time, analysis time, and microscopic field analysis on motility results.

\section{MATERIALS AND METHODS}

\subsection{Animals and semen processing}

\subsubsection{Honey bee colonies}

The experiment was carried out during the beekeeping season (March-June 2018) and included drones reared in honey bee (Apis mellifera iberiensis ) colonies in an apiary near Huesca, Spain (42 $\left.12^{\circ} 01.5^{\prime \prime} \mathrm{N} 0^{\circ} 34^{\prime} 19.1^{\prime \prime} \mathrm{W}\right)$. All colonies were housed in standard Langstroth hives.

\subsubsection{Semen collection and processing}

Flying drones were caught on their return to the hive after blocking the entrance with a queen excluder. Drones were transported to the laboratory, where semen was collected within the first hour after capture using standardized procedures (Cobey et al. 2013). Briefly, the eversion of the endophallus was induced by placing manual pressure on the thorax and, if necessary, on the abdomen. An insemination syringe (Peter Schley, Lich, Germany) was used to collect semen in a capillary tube with an inner diameter of approximately $1 \mathrm{~mm}$. A total of 30 males, 10 males from 3 colonies, were sampled individually. After collection, semen was diluted in a Kiev buffer (K+; Table I; Collins 2005) at an initial ratio of 1:500, and further diluted when necessary to reach the appropriate sperm concentration for the study of individual sperm motility. Diluted semen was divided in two Eppendorf tubes. The first was maintained at room temperature until chamber loading and the second was maintained at $35{ }^{\circ} \mathrm{C}$ for $30 \mathrm{~min}$ before loading. To avoid differences in the elapsed time between dilution of the semen and the loading of the different viewing devices, the order of the chamber analysis was modified for each drone.

\subsection{Viewing chambers and slides}

Samples were analyzed using five different chambers: slide coverslips $(\mathrm{SC} ; 10 \mu \mathrm{L}$ under a $22 \times 22-\mathrm{mm}$ coverslip; Menzel-Gläser, Braunschweig, Germany), Leja $10 \mu \mathrm{m}$ (L10; $10 \mu \mathrm{m}$ deep; Leja Products B.V., Nieuw-Vennep, the Netherlands), Leja $20 \mu \mathrm{m}$ (L20; $20 \mu \mathrm{m}$ deep; Leja), 
Table I. Composition and characteristics of the diluents used for honey bee semen.

\begin{tabular}{|c|c|c|c|c|c|}
\hline Name of diluent & Component & Quantity $(\mathrm{g} / 100 \mathrm{~mL})$ & Concentration $(\mathrm{mM} / \mathrm{L})$ & $\mathrm{pH}$ & $\begin{array}{c}\text { Osmolarity } \\
\text { (mOsm) }\end{array}$ \\
\hline \multirow[t]{4}{*}{ Kiev (K; Ruttner 1976) } & $\mathrm{Na}$ citrate $2 \mathrm{H}_{2} \mathrm{O}$ & 2.43 & 82.62 & \multirow[t]{4}{*}{8.4} & \multirow[t]{4}{*}{285} \\
\hline & $\mathrm{NaHCO}_{3}$ & 0.21 & 25.0 & & \\
\hline & $\mathrm{KCl}$ & 0.04 & 5.37 & & \\
\hline & Glucose & 0.3 & 16.65 & & \\
\hline \multirow[t]{4}{*}{ Kiev high potasium $(\mathrm{K}+)$} & $\mathrm{Na}$ citrate. $2 \mathrm{H}_{2} \mathrm{O}$ & 2.43 & 82.62 & \multirow[t]{4}{*}{8.5} & \multirow[t]{4}{*}{384} \\
\hline & $\mathrm{NaHCO}_{3}$ & 0.21 & 25.0 & & \\
\hline & $\mathrm{KCl}$ & 0.41 & 55.0 & & \\
\hline & Glucose & 0.3 & 16.65 & & \\
\hline \multirow[t]{4}{*}{ Kiev-trehalose (Kt) } & $\mathrm{Na}$ citrate $2 \mathrm{H}_{2} \mathrm{O}$ & 2.43 & 82.62 & \multirow[t]{4}{*}{8.5} & \multirow[t]{4}{*}{390} \\
\hline & $\mathrm{NaHCO}_{3}$ & 0.21 & 25.0 & & \\
\hline & $\mathrm{KCl}$ & 0.41 & 55.0 & & \\
\hline & Trehalose & 1.15 & 30,4 & & \\
\hline \multirow[t]{5}{*}{ Kiev-BSA (Kb) } & $\mathrm{Na}$ citrate. $2 \mathrm{H}_{2} \mathrm{O}$ & 2.43 & 82.62 & \multirow[t]{5}{*}{8.1} & \multirow[t]{5}{*}{385} \\
\hline & $\mathrm{NaHCO}_{3}$ & 0.21 & 25.0 & & \\
\hline & $\mathrm{KCl}$ & 0.41 & 55.0 & & \\
\hline & Glucose & 0.3 & 16.65 & & \\
\hline & BSA & 2.0 & & & \\
\hline
\end{tabular}

ISASD4C10 (IS10; $10 \mu \mathrm{m}$ deep; Proiser R + D S.L., Paterna, Spain), Makler ${ }^{\circledR}$ (MK; $10 \mu \mathrm{m}$ deep; SefiMedical Instruments Ltd., Haifa, Israel).

\subsection{Sperm quality assessment}

\subsubsection{Assessment of sperm motility}

Semen was placed in the viewing chamber and live video pictures were recorded using a setup comprising an Olympus BX40 microscope (Olympus Optical Co., Tokyo, Japan) equipped with a heated stage $\left(35^{\circ} \mathrm{C}\right)$, a 10 times negative phase objective and a Basler digital camera (model acA1920-155 Basler AG, Vision Technologies, Ahrensburg, Germany). Sperm motility was estimated subjectively by a single observer in a blinded manner. Sperm were classified as motile sperm (MS, \%) if they presented any type of active movement (Wegener et al. 2012), freely motile sperm (FS, \%) if the sperm head was not adhered to the glass surface and showed displacement, and circular sperm (CS, \% of motile cells) if the sperm head and tail overlapped. At least 100 cells were examined per sample.

\subsubsection{Evaluation of sperm plasmalemma}

Sperm viability (membrane integrity, SV) was determined using acridine orange and propidium iodide (Yániz et al. 2013). At least 200 cells were examined per sample.

\subsection{Experimental design}

\subsubsection{Study 1: effect of chamber type}

Sperm motility variables were assessed in five chambers (SC, MK, L10, L20, and IS10) with different characteristics.

\subsubsection{Study 2: Effect of incubating samples at $35^{\circ} \mathrm{C}$}

The effect of incubating semen samples at $35{ }^{\circ} \mathrm{C}$ was assessed. Samples were evaluated using L10 chambers after 0 and $30 \mathrm{~min}$ incubation at $35{ }^{\circ} \mathrm{C}$ in an Eppendorf tube. 


\subsubsection{Study 3: effect of time elapsed between sample loading and sperm evaluation}

The effect on sperm motility of time elapsed between sample loading and assessment was determined. Samples were assessed at 0, 5, 15, 30, and $60 \mathrm{~min}$ after loading in the L10 chamber, which was maintained at $35^{\circ} \mathrm{C}$ in a heated stage.

\subsubsection{Study 4: effect of the microscopic field}

\subsection{5. analysis}

The effect of the microscopic field on sperm motility was assessed in six consecutive fields of the L10 chamber.

\subsubsection{Study 5: effect of the diluent}

For a better understanding of the effect of the diluent composition on the results of sperm motility in the different chambers and incubation times, an additional assay was performed using semen of 32 new drones from three colonies. Semen was collected individually and diluted in one of four diluents $(\mathrm{K}, \mathrm{K}+, \mathrm{Kt}$, and $\mathrm{Kb}$; 8 drones for each diluent). Table I shows the composition of the four diluents used in this study. After dilution, semen was loaded in three chambers (SC, MK, L10), that were maintained $5 \mathrm{~min}$ in a heated stage at $35{ }^{\circ} \mathrm{C}$ before sperm motility assessment.

\subsection{Statistical analysis}

The values obtained were expressed as the mean \pm standard error of the mean (SEM). Statistical analyses were performed using SPSS $®$ software, version 15.0 (SPSS Inc., Chicago, IL, USA). Distribution normality and the homogeneity of variance of the median for each set were checked using the Kolmogorov-Smirnov and Levene tests respectively. As samples were nonnormally distributed, differences in sperm motility between devices and between different fields were recorded by means of the Kruskal-Wallis test, followed by the Mann-Whitney post hoc test. The statistical level of significance was set at $P<0.05$.

\section{RESULTS}

\subsection{Study 1}

The average sperm viability of the 30 drone samples included in this study was $70.58 \pm 1.92$ (mean $\pm \mathrm{SEM}$ ). The effects of the sample viewing devices (SC, MK, L10, L20 and IS10 chambers) on sperm motility parameters are shown in Figure 1. Significant differences $(P<0.001)$ were observed for all parameters studied. A lower proportion of motile sperm was observed in SC chambers than in capillary-loaded chambers, with mean differences of $18.0 \%, 14.5 \%$, and $17.0 \%$ for L10, L20 and IS10 viewing chambers, respectively. The percentage of freely moving sperm was much lower in drop-loaded (SC and MK) compared with capillary-loaded chambers (L10, L20 and ISAS), while the percentage of circular sperm showed a contrasting trend (Figure 1).

\subsection{Study 2}

The incubation of the semen sample at $35^{\circ} \mathrm{C}$ in an Eppendorf tube before chamber loading had no effect on sperm motility parameters, as there was no difference between observations at 0 and $30 \min (P=0.579,0.442$, and 0.887 for MS, $\mathrm{FS}$, and CS, respectively).

\subsection{Study 3}

The effects on sperm motility of time elapsed between sample loading on L10 chambers and assessment are shown in Figure 2. A significant increase in MS and CS was observed after $30 \mathrm{~min}$ of incubation in the chamber, while PS increased significantly after $60 \mathrm{~min}$ of incubation in comparison with the same parameter at $t=0$. However, no significant differences in MS and FS were detected for elapsed times of greater than $5 \mathrm{~min}$. Conversely, CS was significantly higher after 60 min compared with all other incubation periods.

\subsection{Study 4}

Figure 3 shows the effects of the microscopic field analysis in the L10 chamber on the sperm motility parameters. No significant differences in 


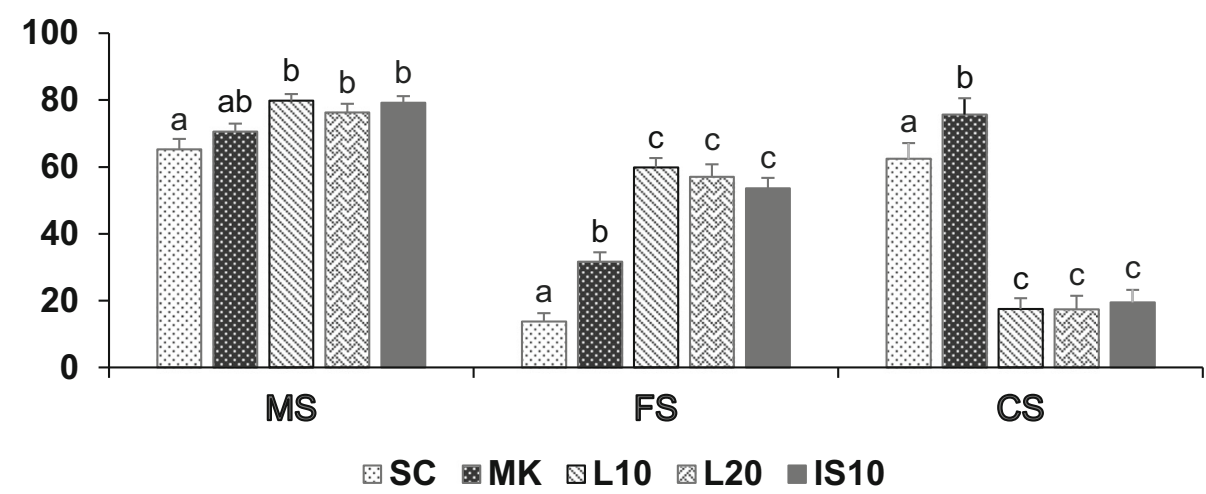

Figure 1 Mean + SEM motility values from honey bee drone semen samples evaluated with different viewing devices: slide-coverslip (SC), Makler (MK), Leja 10 (L10), Leja 20 (L20), and ISAS10 (IS10) chambers. MS, sperm motility percentage; FS, freely moving sperm; CS, circularly moving sperm (\% of MS). Superscripts (a-c) denote differences between devices $(P<0.001)$.

MS were observed as the number of fields analyzed increased. However, FS decreased, and CS increased in the last fields to be analyzed (Figure 3).

\subsection{Study 5}

The effect of chamber type (SC, MK, L10) for the four diluents used in this study $(\mathrm{K}, \mathrm{K}+, \mathrm{Kt}$, and $\mathrm{Kb}$ ) are depicted in Figure 4. A lower proportion of motile sperm was observed in SC and MK chambers than in $\mathrm{L} 10$ chamber for $\mathrm{K}, \mathrm{K}+$, and $\mathrm{Kt}$ diluents. Using these diluents, the percentage of freely moving sperm was much lower in SC and MK compared with L10 chamber. The percentage of circular sperm was higher using the MK chambers for most diluents (Figure 4). With the $\mathrm{K}$ diluent, the presence of some spermatozoa showing signs of hypo-osmotic stress, as evidenced by curling/swelling, was observed. The addition of BSA to the media ( $\mathrm{Kb}$ diluent) clearly reduced sperm adhesion to glass surface, so that

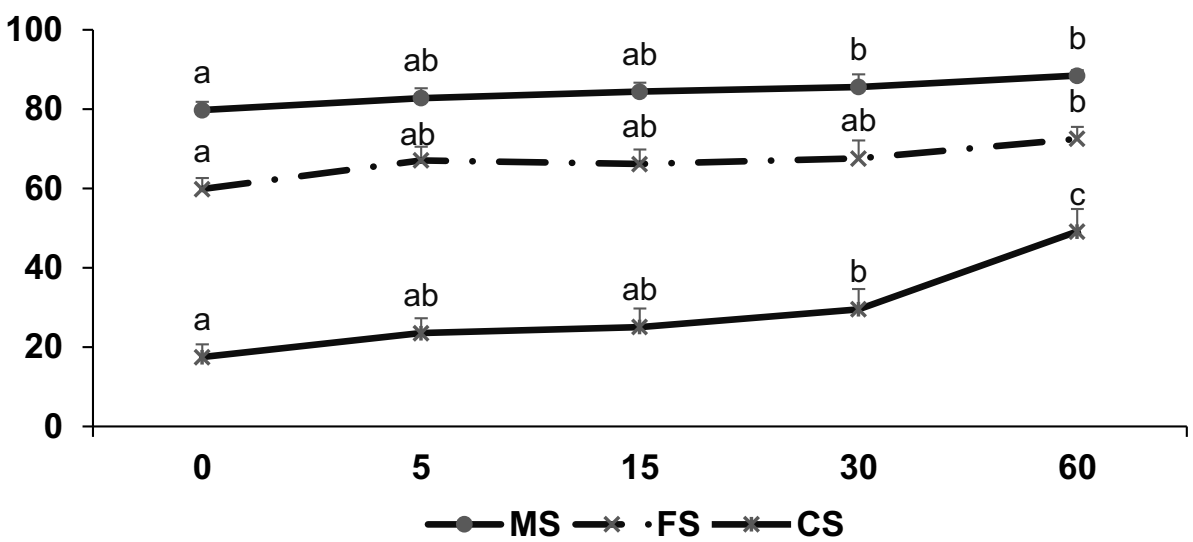

Figure 2 Mean + SEM motility values from honey bee drone semen samples measured in function of time elapsed between loading samples on Leja 10 chambers and assessment. MS, sperm motility percentage; FS, freely moving sperm; CS, circularly moving sperm (\% of MS). Superscripts $(\mathrm{a}-\mathrm{c})$ denote differences between elapsed times $(P<0.001)$. 


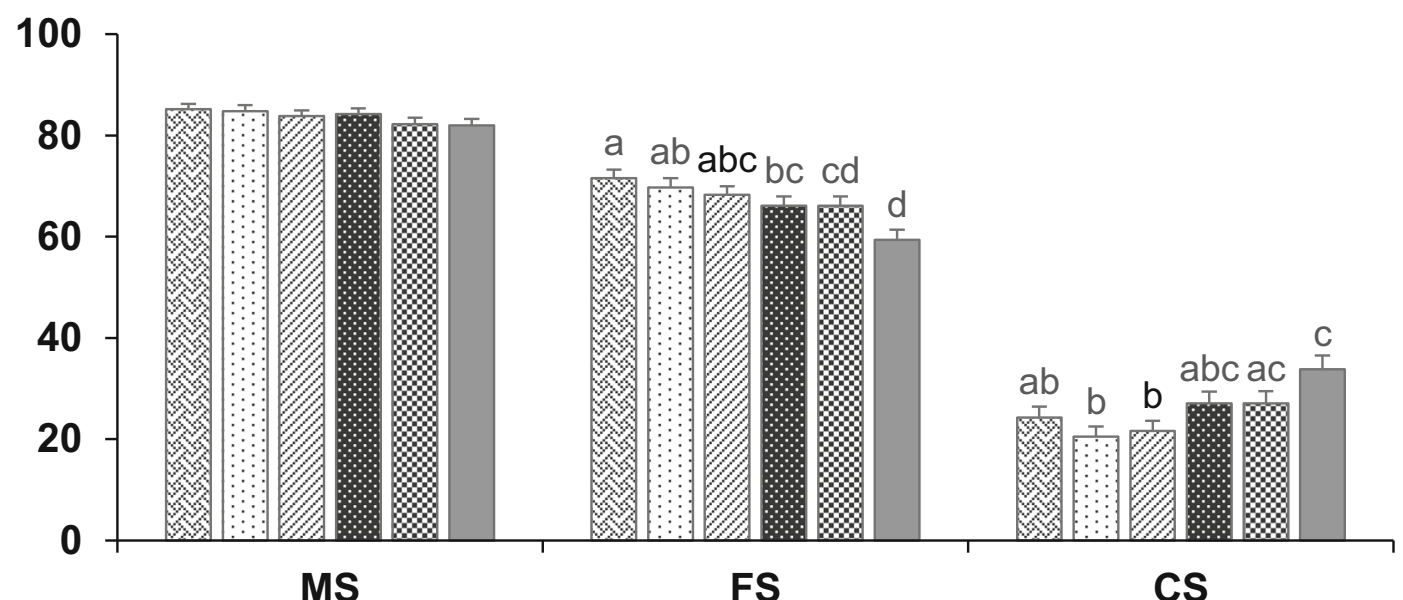

\section{图 $\square 2 \square 3$ : 4 : 56}

Figure 3 Mean + SEM motility values from honey bee drone semen samples measured in six consecutive microscopic fields on Leja 10 chambers. MS, sperm motility percentage; FS, freely moving sperm; CS, circularly moving sperm (\% of MS). Superscripts $(\mathrm{a}-\mathrm{d})$ denote differences between fields $(P<0.001)$.

no significant differences in MS were detected between chambers, nor in FS between MK and L10 chambers. A higher proportion of spermatozoa showing linear trajectories (snake-like forms) was also observed when semen was diluted in the $\mathrm{Kb}$ diluent.

\section{DISCUSSION}

The evaluation of sperm motility in drones may be of interest in both routine sperm analyses and experimental studies. Measurements, however, may be affected by multiple factors such as the type of chamber, semen incubation, and time between sample deposition and measurement. Consequently, it is essential to standardize measurement conditions in order to compare results from different sperm motility assessments. We are unable to find any studies in the literature evaluating the effect of different chambers or measurement conditions on honey bee sperm motility. In the present work, we studied various factors affecting the assessment of drone sperm motility.

Firstly, we studied the effect of chamber type. Most studies into drone sperm motility use slide coverslips (Locke and Peng 1993; Taylor et al. 2009; Wegener et al. 2012; Ciereszko et al. 2017).
However, here we have clearly shown that the use of this viewing device reduces the percentage of motile and of freely moving sperm compared with Leja and ISAS chambers, which are preferable for use in this species. The effects of chamber type on sperm motility was greater in the honey bee than those described in several mammalian species (Contri et al. 2010; Lenz et al. 2011; Gloria et al. 2013; Palacín et al. 2013; Del Gallego et al. 2017; Bompart et al. 2018), where specific chambers were also recommended instead of SC.

Material composition and the number of ions exposed at the surface of the glass might explain the differences in sperm motility between chambers (Bompart et al. 2018). Using diluents without proteins, drone spermatozoa appear to be highly sensitive to the composition of the glass used in chambers, with heads adhering to the glass surface but still showing flagellar movement. This characteristic clearly reduces the percentage of freely moving spermatozoa in SC and MK chambers compared with the L10, L20, and IS10 chambers. Similar properties have also been described in some mammalian species, for example pig (Yaniz et al. 2018).

The depth and design of the chamber may also influence sperm motility, either by restricting 

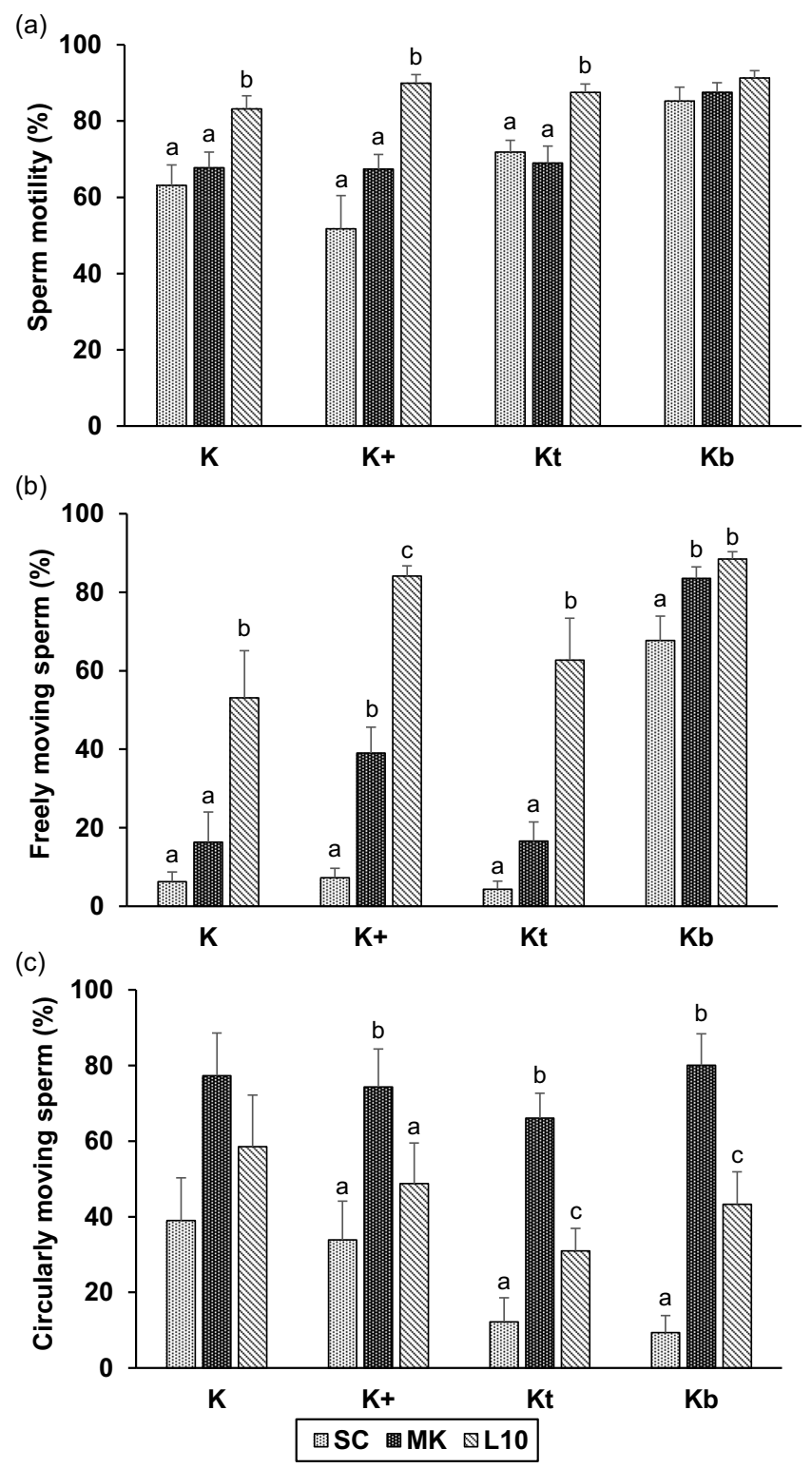

Figure 4 Mean +S.E.M. motility values from honey bee drone semen samples diluted in four different diluents and evaluated with different viewing devices: percentage of total sperm motility (a) freely moving sperm (b) and circularly moving sperm (\% of MS; c). SC, slide-coverslip; MK, Makler; L10, Leja 10; K, Kiev diluent; K+, Kiev diluent with high $\mathrm{KCl} ; \mathrm{Kt}, \mathrm{K}+$ with trehalose; $\mathrm{Kb}, \mathrm{K}+$ with $2 \% \mathrm{BSA}$. Superscripts (a-c) denote differences between devices $(P<0.001)$.

displacement or through interactions with the chamber walls (Verstegen et al. 2002). In the present study, however, these factors had little impact on sperm motility results in capillaryloaded chambers. Consequently, the use of 10$\mu \mathrm{m}$ deep chambers may be preferable to devices which are $20-\mu \mathrm{m}$ or deeper as this latter group complicates the analysis of all cells because they are moving in different focal planes.

In previous studies, some authors proposed that incubating diluted drone sperm samples for 1530 min at $35^{\circ} \mathrm{C}$ before loading them on the slide 
coverslips (Wegener et al. 2012; Ciereszko et al. 2017). Our results (study 2) do not support the need for this sample pre-incubation period, since the motility parameters were essentially unchanged after $30 \mathrm{~min}$ incubation at $35^{\circ} \mathrm{C}$.

The time elapsed between sample loading in L10 chambers and measurement influenced motility parameters (study 3); values were increased when the chamber was maintained at $35{ }^{\circ} \mathrm{C}$ using a heated stage compared with results at $t=0$. However, after 5 min of incubation, no significant differences in MS and FS were detected for the different incubation times. In agreement with our results, but while using slide coverslips and without specifying temperature conditions, Locke and Peng (1993) also incubated the loaded slides in the microscope stage for $5 \mathrm{~min}$ because they observed that sperm motility increased during the first 3 min after the slide was placed on the stage. The percentages of circular sperm increased progressively throughout the incubation period but, as mentioned above, this parameter does not provide clear evidence of better sperm quality.

When the effect of microscopic field was assessed in study 4 , total sperm motility was similar in all fields analyzed, as was previously observed in bulls (Nothling and dos Santos 2012). Regarding freely moving sperm, a significant decrease was observed as more fields were analyzed, in agreement with a previous study in goats (Del Gallego et al. 2017). It seems unlikely that this decrease in FS could be due to the time elapsed between measurements in the different fields, as in study 3 , the time elapsed between sample loading on the chambers and sperm assessment increased FS. The decrease could be attributed, however, to the inhibitory effect of the microscope light on the drone sperm or to the design of the Leja chamber used in the study. Again, the percentages of circular sperm increased progressively as more fields were analyzed, thus revealing a different trend to other motility parameters.

The diluent composition clearly influenced the results of sperm motility, particularly in the SC and MK chambers (study 5). The Kiev diluent is the media most frequently used in the bibliography for drone sperm motility assessment (Locke and Peng 1993; Taylor et al. 2009; Wegener et al. 2012; Ciereszko et al. 2017). Two different Kiev formulas have been described for drone semen. The original Kiev diluent, with a low osmolarity, was described by Ruttner (1976). In our opinion, this diluent should not be recommended for drone semen as increased the number of spermatozoa with sings of osmotic stress. This diluent was later modified through increasing the $\mathrm{KCl}$ concentration and osmolarity (Collins 2005). Verma (1973) described that the osmolarity of the drone semen and of the seminal plasma was 467 and $325 \mathrm{mOsmol} / \mathrm{L}$, respectively. The modified Kiev diluent $(\mathrm{K}+)$ described by Collins (2005) has an intermediate value between this range (384), and consequently was selected for the majority of the studies in this research work.

Sperm motility should better be evaluated in a medium that does not limit cell activity. Motility and osmolarity are connected, as honey bee sperm are inactivated by media with high osmotic pressure (Verma 1974; Wegener et al. 2014), and their use should not be recommended for sperm motility assessment in this species. Other factors, like the presence of sugars, are clearly important as their inclusion in the diluent activate drone sperm motility (Poole and Edwards 1970). If diluents without sugars were used the onset of motility may be retarded and, under these circumstances, it may be more relevant to incubate semen before analysis.

The addition of BSA to the diluent reduced the adhesion of spermatozoa to the glass surface of SC and MK chambers (study 5). A similar effect was observed in human sperm, were the addition of BSA to the sperm washing solution partially reversed the adhesion of spermatozoa to the glass (Armant and Ellis 1995).

Leja and ISAS chambers are manufactured to prevent sticking of the sperm to the surface, so that drone sperm can be evaluated for motility with more consistent results, both in the presence and absence of protein. In human, the use of nitrocellulose and polyvinyl glass coatings prevent sperm adhesion without affecting the motility (Chapeau and Gagnon 1987).

\section{CONCLUSIONS}

This study demonstrates that the choice of chamber and the diluent used to measure honey bee drone sperm motility has a significant effect on results. Leja and ISAS disposable chambers seemed to give reliable results with negligible effects on sperm motility parameters, even when 
the measurement was made a long time after loading the chamber or using media without proteins. If the semen is diluted in media containing $2 \%$ BSA, the use of the Makler chamber may also provide reliable results. A minimum elapsed time of 5 min between chamber loading and sperm motility assessment is recommended for drones. Total sperm motility may be a better indicator of semen quality in drones than the other parameters analyzed, as is less prone to bias due to uncontrolled variation in experimental conditions.

\section{AUTHORS' CONTRIBUTIONS}

JY conceived this research, designed and performed experiments and analysis, and wrote the paper; IP and PS participated in the design, the experiments and participated in the revisions of it.Funding information

This work was supported by the Spanish MINECO (grant AGL2017-85030-R), and the DGA-FSE (grant A07_17R).

Effet des caractéristiques de la chambre, de l'incubation et du diluant sur la motilité du sperme de bourdon d'abeille mellifère (Apis mellifera)

\section{Apis mellifera iberiensis / sperme}

Auswirkungen der Charakteristika der Kammer, der Inkubation und des Verdünnungsmittels auf die Beweglichkeit von Spermien von Drohnen der Honigbiene (Apis mellifera)

\section{Apis mellifera iberiensis / Spermien / Beweglichkeit}

\section{REFERENCES}

Armant, D.R., Ellis, M.A., (1995). Improved Accuracy of Sperm Motility Assessment Using a Modified MicroCell Sperm Counting Chamber. Fertil. Steril. 63, 1128-1130

Ben Abdelkader, F., Kairo, G., Tchamitchian, S., Cousin, M., Senechal, J., Crauser, D., Vermandere, J.P., Alaux, C., Le Conte, Y., Belzunces, L.P., Barbouche, N., Brunet, J.L., (2014) Semen quality of honey bee drones maintained from emergence to sexual maturity under laboratory, semi-field and field conditions. Apidologie 45, 215-223

Bompart, D., Garcia-Molina, A., Valverde, A., Caldeira, C., Yaniz, J., Nunez de Murga, M., Soler, C. (2018) CASA-Mot technology: how results are affected by the frame rate and counting chamber. Reprod. Fertil. Dev. 30, 810-819

Chapeau, C., Gagnon, C. (1987) Nitrocellulose and polyvinyl coatings prevent sperm adhesion to glass without affecting the motility of intact and demembranated human spermatozoa. J. Androl. 8, 34-40

Ciereszko, A., Wilde, J., Dietrich, G.J., Siuda, M., Bak, B., Judycka, S., Karol, H. (2017) Sperm parameters of honeybee drones exposed to imidacloprid. Apidologie 48, 211-222

Cobey, S.W.,. Tarpy, D.R, Woyke, J. (2013) Standard methods for instrumental insemination of Apis mellifera queens. J. Apicult. Res. 52, 1-18

Collins, A.M. (2000) Relationship between semen quality and performance of instrumentally inseminated honey bee queens. Apidologie 31, 421-429.

Collins, A.M. (2003) A scientific note on the effect of centrifugation on pooled honey bee semen. Apidologie 34, $469-470$

Collins, A.M. (2004a) Functional longevity of honey bee, Apis mellifera, queens inseminated with low viability semen. J. Apicult. Res. 43, 167-171.

Collins, A.M. (2004b) Sources of variation in the viability of honey bee, Apis mellifera L., semen collected for artificial insemination. Invertebr. Reprod. Dev. 45, 231-237

Collins, A.M. (2005) Insemination of honey bee, Apis mellifera, queens with non-frozen stored semen: sperm concentration measured with a spectrophotometer. J. Apicult. Res. 44, 141-145

Collins, A.M., Pettis, J.S. (2001) Effect of varroa infestation on semen quality. Am. Bee J. 141 , 590-593

Contri, A., Valorz, C., Faustini, M., Wegher, L., Carluccio, A. (2010) Effect of semen preparation on casa motility results in cryopreserved bull spermatozoa. Theriogenology 74, 424-435

Czekonska, K., Chuda-Mickiewicz, B., Chorbinski, P. (2013a) The effect of brood incubation temperature on the reproductive value of honey bee (Apis mellifera ) drones. J. Apicult. Res. 52, 96-105

Czekonska, K., Chuda-Mickiewicz, B., Chorbinski, P. (2013b) The influence of honey bee (Apis mellifera) drone age on volume of semen and viability of spermatozoa. J. Apic. Sci. 57, 61-66

Czekonska, K., Chuda-Mickiewicz, B., Samborski, J. (2015) Quality of honeybee drones reared in colonies with limited and unlimited access to pollen. Apidologie 46, 1-9

Del Gallego, R., Sadeghi, S., Blasco, E., Soler, C., Yaniz, J.L., Silvestre, M. A. (2017) Effect of chamber characteristics, loading and analysis time on motility and kinetic variables analysed with the CASA-mot system in goat sperm. Anim. Reprod. Sci. 177, 97-104 
DelCacho, E., Marti, J.I., Josa, A., Quilez, J., SanchezAcedo, C. (1996) Effect of Varroa jacobsoni parasitization in the glycoprotein expression on Apis mellifera spermatozoa. Apidologie 27, 87-92

den Boer, S.P.A., Boomsma, J.J., Baer, B. (2009) Honey bee males and queens use glandular secretions to enhance sperm viability before and after storage. J. Insect. Physiol. 55, 538-543

Gajger, I.T., Sakac, M., Gregorc, A. (2017) Impact of thiamethoxam on honey bee queen (Apis mellifera carnica ) reproductive morphology and physiology. Bul. Environ. Contam. Toxicol. 99, 297-302

Gloria, A., Carluccio, A., Contri, A., Wegher, L., Valorz, C., Robbe, D. (2013) The effect of the chamber on kinetic results in cryopreserved bull spermatozoa. Andrology 1, 879-885

Hopkins, B.K., Herr, C. (2010). Factors affecting the successful cryopreservation of honey bee (Apis mellifera) spermatozoa. Apidologie 41, 548-556

Hopkins, B.K., Cobey, S.W., Herr, C., Sheppard, W.S. (2017). Gel-coated tubes extend above-freezing storage of honey bee (Apis mellifera) semen to 439 days with production of fertilised offspring. Reprod. Fertil. Dev. 29, 1944-1949

Johnson, R.M., Dahlgren, L., Siegfried, B.D., Ellis, M.D. (2013) Effect of in-hive miticides on drone honey bee survival and sperm viability. J. Apicult. Res. 52 , 88-95

Lenz, R.W., Kjelland, M.E., Vonderhaar, K., Swannack, T.M., Moreno, J.F. (2011) A comparison of bovine seminal quality assessments using different viewing chambers with a computer-assisted semen analyzer. J. Anim. Sci. 89, 383-388

Locke, S.J., Peng, Y.S. (1993) The effects of drone age, semen storage and contamination on semen quality in the honeybee (Apis mellifera). Physiol. Entomol. 18, 144-148

Lodesani, M., Balduzzi, D., Galli, A. (2004) Functional characterisation of semen in honeybee queen $(A . m$. ligustica) spermatheca and efficiency of the diluted semen technique in instrumental insemination. Ital. J. Anim. Sci. 3, 385-392

Marti, J.I., Del Cacho, E., Josa, A., Espinosa, E., MuiñoBlanco, T. (1996) Plasma membrane glycoproteins of mature and inmature drone honey bee (Apis mellifera $L$.) spermatozoa: lecting-binding as seen by light and electron microscopy. Theriogenology 46, 181-190

Nothling, J.O., dos Santos, I.P. (2012) Which fields under a coverslip should one assess to estimate sperm motility? Theriogenology 77, 1686-1697

Nur, Z., Seven-Cakmak, S., Ustuner, B., Cakmak, I., Erturk, M., Abramson, C. I., Sagirkaya, H., Soylu, M. K. (2012) The use of the hypo-osmotic swelling test, water test, and supravital staining in the evaluation of drone sperm. Apidologie 43, 31-38

Palacín, I., Vicente-Fiel, S., Santolaria, P., Yániz, J.L. (2013) Standardization of CASA sperm motility assessment in the ram. Small. Rum. Res. 112, 128-135

Pettis, J.S., Rice, N., Joselow, K., van Engelsdorp, D., Chaimanee, V. (2016) Colony failure linked to low sperm viability in honey bee (Apis mellifera) queens and an exploration of potential causative factors. PloS One 11, e0147220

Rhodes, J.W., Harden, S., Spooner-Hart, R., Anderson, D.L., Wheen, G. (2011) Effects of age, season and genetics on semen and sperm production in Apis mellifera drones. Apidologie 42, 29-38

Rousseau, A., Fournier, V., Giovenazzo, P. (2015) Apis mellifera (Hymenoptera: Apidae) drone sperm quality in relation to age, genetic line, and time of breeding. Can. Entomol. 147, 702-711

Ruttner, F. (1976). The Instrumental Insemination of the Queen Bee. Apimondia Publishing House. Bucharest.

Schluns, H., Schluns, E.A., van Praagh, J., Moritz, R.F.A. (2003) Sperm numbers in drone honeybees (Apis mellifera) depend on body size. Apidologie 34, 577584.

Shafir, S., Kabanoff, L., Duncan, M., Oldroyd, B.P. (2009) Honey bee (Apis mellifera) sperm competition in vitro - two are no less viable than one. Apidologie 40, 556561

Stürup, M., Baer-Imhoof, B., Nash, D.R., Boomsma, J.J., Baer, B. (2013) When every sperm counts: factors affecting male fertility in the honeybee Apis mellifera. Behav. Ecol., 24, 1192-1198

Taylor, M.A., Guzman-Novoa, E., Morfin, N., Buhr, M.M. (2009) Improving viability of cryopreserved honey bee (Apis mellifera L.) sperm with selected diluents, cryoprotectants, and semen dilution ratios. Theriogenology 72, 149-159

Verstegen, J., Iguer-Ouada, M., Onclin, K. (2002) Computer assisted semen analyzers in andrology research and veterinary practice. Theriogenology 57, 149-179

Wegener, J., May, T., Knollmann, U., Kamp, G., Muller, K., Bienefeld, K. (2012) In vivo validation of in vitro quality tests for cryopreserved honey bee semen. Cryobiology 65, 126-131

Wegener, J., May, T., Kamp, G., Bienefeld, K. (2014) A successful new approach to honeybee semen cryopreservation. Cryobiology 69, 236-242

Yániz, J.L., Palacín, I., Vicente-Fiel, S., Gosálvez, J., López-Fernández, C., Santolaria, P. (2013) Comparison of membrane-permeant fluorescent probes for sperm viability assessment in the ram. Reprod. Domest. Anim. 48, 598-603

Yaniz, J.L., Silvestre, M.A., Santolaria, P., Soler, C. (2018) CASA-Mot in mammals: an update. Reprod. Fertil. Dev. 30, 799-809

Zaitoun, S., Al-Ghzawi, A.A.M., Kridli, R. (2009) Monthly changes in various drone characteristics of Apis mellifera ligustica and Apis mellifera syriaca. Entomol. Sci. 12, 208-214

Publisher's note Springer Nature remains neutral with regard to jurisdictional claims in published maps and institutional affiliations. 